first published in 1989, namely:

1. The social view of health that recognises that:

- health is determined by a broad range of social, environmental, economic and biological factors;

- differences in health status and health outcomes are linked to gender, age, socioeconomic status, ethnicity, disability, location and environment;

- health promotion, disease prevention, equity of access to appropriate and affordable services, and strengthening the primary health care system are necessary, along with high-quality illness treatment services;

- information, consultation and community development are important elements of the health process.

2. Women's health policy must encompass all of women's lifespan and reflect women's various roles in Australian society, not just their reproductive role.

3. Greater participation by women in decision-making about health services and health policy, as both consumers and providers must be promoted.

4. Women's rights to be treated with dignity in an environment that provides for privacy, informed consent and confidentiality must be recognised.

5. Informed decisions require accessible information that is appropriately targeted for different socio-economic, educational and cultural groups.

6. Accurate data and research concerning women's health, women's views about health and strategies that most effectively address women's health needs are essential as a basis for developing, implementing and evaluating policy.$^{5}$

Yet there is no cause for complacency. The issue of women's health has not entered the mainstream as effectively as it could have. ${ }^{6}$ Other global movements, such as health improvement, equity, social capital or quality may well overtake women's health as catalysts for health reform across NSW. As each of these can trace their origins back to the broader social changes of the 1970s from which feminism also developed, it would seem that women's health has little to fear. Or has it?

This first of a two-part series to appear in the NSW Public Health Bulletin contains essential reading for those eager to learn the current status of women's health in NSW. Elena Murty summarises new directions in policy development, placing in context the recent Strategic Framework to Advance the Health of Women. Pickett describes the work of the Older Women's Network, Moore and Connolly describe the results of an evaluation of a community intervention to raise awareness about domestic violence, Boyce identifies how early intervention strategies could be used to prevent women developing postnatal depression and, finally, Purcell describes the effect of smoking on women's health. The second issue in the series will focus on women's health research.

\section{REFERENCES}

1. NSW Women's Advisory Council to the Premier. A decade of change: Women in New South Wales 1976-1986. Sydney: NSW Government Printer, 1987.

2. Ward J, Hindmarsh E, Knowlden S, McMurchie M, Unwin W. A course of advanced training for general practitioners in women's health. Healthright 1989; 8: 18-21.

3. Screening Evaluation Co-ordination Unit. Breast cancer screening in Australia: Future directions. Prevention program evaluation series No 1. Canberra: AGPS, 1990.

4. Screening Evaluation Co-ordination Unit. Cervical cancer screening in Australia: Options for change. Prevention program evaluation series No 2. Canberra: AGPS, 1990.

5. Commonwealth Department of Community Services and Health. National Women's Health Policy: Advancing women's health in Australia. Canberra: AGPS, 1989.

6. Commonwealth Department of Health, Housing, Local Government and Community Services. National Women's Health Program: Evaluation and future directions. Canberra: AGPS, 1993. it

\title{
NEW WAYS OF THINKING ABOUT WOMEN'S HEALTH
}

\section{Elena Murty}

Senior Policy Analyst, Women's Health

Health Services Policy Branch

NSW Department of Health

The NSW Department of Health has recently released in draft form a Strategic Framework to Advance the Health of Women. Developed through an extensive consultation process begun in 1996, it represents the next step in an ongoing commitment to develop and improve the policies and services that support the health of women in NSW. This article describes the rationale supporting the development of the strategy and its principal elements.

\section{BACKGROUND}

In June 1996 women comprised 50.2 per cent of the NSW population. ${ }^{1}$ They are both major users of health services and providers of a large proportion of formal and informal health care through their participation in the NSW Health workforce and as health carers in the family-private sphere. 
The reasons why women become ill, and how they stay healthy, are often different to the experience of men as a result of their differing roles, responsibilities and access to resources. Consequently, gender is increasingly recognised by the health care system as a determinant of health.

Over the past three decades there have been many changes to health services to improve their responsiveness to women's needs and to ensure that they are delivered in an appropriate manner. The National Women's Health Policy (1989), ${ }^{2}$ and the implementation of the National Women's Health Program in NSW have helped to reorient health services to be more responsive to the social influences that affect the health and wellbeing of women. Positions such as women's health coordinators have been created, and a comprehensive range of services, such as birth centres and sexual assault units, have been established.

The pattern of illness and health experienced by women is changing. More young women at secondary school smoke than do young men. ${ }^{3}$ While breast cancer is the most common form of malignant cancer and the leading cause of cancer-related death in women, lung cancer is the second most common cause of cancer-related death. Indeed, as male death rates from lung cancer decline, female rates continue to rise. ${ }^{3}$

Low socio-economic status is linked with poor health and women are affected disproportionately. For example, in 1996,57 per cent of women in the workforce aged 15 years and over had a weekly income less than $\$ 300$ compared to 37 percent of men. ${ }^{3}$

The number of Apprehended Violence Orders is increasing. ${ }^{4}$ The report Women's Safety Australia 1996 estimated that, of women aged 15 years and over, 2.2 million had suffered physical violence and 1.2 million had suffered sexual violence. ${ }^{5,6}$ Violence directed towards pregnant women is associated with higher maternal rates of depression, suicide attempts, and tobacco, alcohol and illicit drug use. ${ }^{7}$

\section{KEY POLICIES IN WOMEN'S HEALTH}

Several policies of the past decade have informed current policy and practice.

\section{The National Women's Health Policy (1989)}

This policy identified seven priority health issues and five key action areas. The priority health issues were:

- reproductive health and sexuality

- health of ageing women

- emotional and mental health

- violence against women

- occupational health and safety

- health needs of carers

- health effects of sex role stereotyping on women.
The key action areas were:

- improving health services for women

- providing health information for women

- researching and collecting data on the health of women

- ensuring women's participation in decision-making about health

- training health care providers.

The National Women's Health Program

An initiative managed by the Commonwealth Department of Human Services and Aged Care, who provided funds to the NSW Department of Health to support the implementation of the National Women's Health Policy on a 50:50 cost-shared basis. These program funds have been instrumental in establishing comprehensive women's health services across NSW to address the priorities and key action areas identified within the policy. Positions for women's health coordinators were established in each Area Health Service. They have become agents for change, influencing mainstream health services to adopt practices congruent with the National Women's Health Policy. There have been many achievements: for example, the program has been influential in improving access to health services for marginalised women, particularly women from nonEnglish speaking backgrounds, rural women and Aboriginal and Torres Strait Islander women; and the participation by women on key committees in Area Health Services has increased.

\section{Women's Health in NSW: A Guide to Health Improvement for Women 1998-2003}

The development and release of this discussion paper identified broad strategic directions for improving the health of women in NSW. ${ }^{8}$ This document, which incorporates a social view of health, addresses the health issues of women with the greatest need and takes a health outcomes approach.

NSW Strategic Directions for Health 1998-2003

This strategy identifies the four principal goals for the NSW health system: healthier people, fairer access, quality health care and better value. ${ }^{9}$

\section{THE STRATEGIC FRAMEWORK TO ADVANCE THE HEALTH OF WOMEN}

The goal of this strategic framework is 'to improve the health and well-being of all women, with a focus on those most at risk, and to encourage the health system to be more responsive to the needs of women' ${ }^{10}$ It promotes a social view of health, which recognises the links between social experiences, position within society, and health status. The strategy directs mainstream and womenspecific health services to work to reduce the inequalities in health between men and women, and also between groups of women. The key elements of the framework are:

Women's health is the business of every health worker Advancing the health of women is a responsibility shared 
by all health workers and is not just the responsibility of women's health workers.

\section{Reducing inequalities between men and women}

Women and men differ in their roles and responsibilities and in their access to resources, including social and economic resources. These factors affect the health of women. The strategy acknowledges that the health system often reinforces these inequities.

\section{Reducing inequalities in health between women}

Not all women have the same opportunities for health. While maintaining a commitment to continue to improve the health of all women, the strategy will target groups of women who evidence suggests tend to have poorer health outcomes than other women. This includes groups such as:

- Aboriginal and Torres Straight Islander women

- women of non-English speaking background

- women with disabilities

- women of low socio-economic status

- women carers

- older women

- young women

- rural women.

The strategic framework will encourage health services to:

- identify groups of disadvantaged women and those with the poorest health outcomes

- target services and programs to address their particular health issues

- identify and address gaps in service provision.

\section{FOUR KEY STRATEGIC DIRECTIONS}

The strategic framework promotes:

\section{Incorporating a gendered approach to health}

The term 'gender' refers to certain roles, characteristics, responsibilities and expectations that our society ascribes on the basis of being female or male. The framework recognises that gender leads to different social, economic and political opportunities for women and men. These inequalities can create, maintain or exacerbate exposure to risk factors that endanger health. In order to identify and act on inequalities that arise from gender, the adoption of a gendered approach to health is required.

Service and policy development activities need to incorporate a gendered approach, and identify and evaluate their potential effects on women and men. In 2000, the NSW Department of Health will be releasing the Gender Equity in Health policy and gender equity checklists for policy and frontline service staff to assist in this process.

\section{Working in collaboration with others to address the social determinants of health}

In the past, health programs and policies tended to emphasise the biological aspects of health care, focusing on the bio-medical models of diagnosis, treatment and prevention of an individual's ill health. They often neglected other factors, such as the social and the economic, that affect the health of women.

The way forward in women's health requires a commitment to address a much broader range of factors influencing the health of women. To do this effectively, the NSW health system will need to work collaboratively with women in the community, other government departments, nongovernment agencies, advocacy groups, general practitioners and the private sector. This intersectoral collaboration will improve the capacity of the health system to maximise health outcomes for women and to develop measures reflecting social determinants that affect health outcomes for women.

\section{Advancing research on women's health experience and morbidity}

The health needs of women need to be represented adequately on the health research agenda. Research topics that are undertaken in epidemiological and clinical research areas have been criticised for not being equally relevant to both sexes and women not always being included in appropriate numbers among the subjects of research.

The challenge is to understand all health issues through a gender analysis. Research is needed to examine the way in which gender affects a wide range of priority public health issues, such as cardiovascular disease, smoking and mental health. Such research is necessary to determine the critical health issues for women and the effect of gender on health outcomes.

\section{Applying a health outcomes approach to women's health}

The Strategic Framework recognises that developing a health outcomes approach means that health services will need to measure a range of indicators, including social, economic and biological, to improve the health of women and, in particular, disadvantaged women.

Developing indicators that can adequately report on women's health outcomes is an important strategic direction to advance the provision of services to women.

\section{GUIDING PRINCIPLES}

The following principles underpin the development and implementation of the strategic framework:

- adopting a social view of health

- empowerment

- supporting primary health care principles

- recognising lifespan roles of women

- intersectoral partnerships

- participation of women in decision-making

- accessibility of services. 


\section{CONCLUSION}

Health services need to continually adapt to the changing conditions that influence the health of women. From 1999, the NSW Department of Health will fund projects and programs that will contribute to implementing the Strategic Framework to Advance the Health of Women across the health system.

\section{REFERENCES}

1. Australian Bureau of Statistics/Office of the Status of Women. Australian Women's Year Book 1997. Canberra: AGPS, 1997.

2. Commonwealth Department of Community Services and Health. National Women's Health Policy (1989). Canberra: AGPS, 1989.

3. NSW Department of Health. The Health of the People of NSW: Report of the Chief Health Officer 1997. Sydney: NSW Department of Health,1997.

4. Criminal Law Review Division. Apprehended violence orders: A Review of the Law Discussion Paper (August 1999). Unpublished.

5. Royal Australasian College of Physicians. For richer, for poorer, in sickness and in health: The socio-economic determinants of health. Sydney: RACP, 1999.

6. Australian Bureau of Statistics: Women's Safety Australia 1996. Canberra: AGPS, 1996.

7. Parker B, McFarlane J, Soeken K, Silva C, Reel S. Testing an intervention to prevent further abuse in pregnant women. Research in Nursing and Health 1999; 22: 59-66.

8. NSW Department of Health. Women's Health in NSW: A Guide to Health Improvement for Women 1998-2003. Unpublished.

9. NSW Department of Health. Strategic directions for health 1998-2003. Sydney: NSW Department of Health, 1998.

10. NSW Department of Health: The Strategic Framework to Advance the Health of Women: Draft (1999). W

Copies of the draft Strategic Framework to Advance the Health of Women can be obtained from Elena Murty by phone (02) 9391 9587, by fax (02) 9391 9615, or by email emurt@doh.health.nsw.gov.au

\section{OLDER WOMEN'S WELLNESS}

\section{Mary-Kate Pickett}

Policy Analyst, Women's Health

Health Services Policy Branch

NSW Department of Health

The stereotyped public image of older women is one of dependence and poor health. The reality is that older women are more often caring for a partner, spouse, neighbour or family member. Therefore, older women have an important role in providing support services in the community. ${ }^{1}$ This article describes the work of the Older Women's Network to promote the wellbeing of older women.

Older women represent the majority within our ageing population. Gender as well as social, biological and economic factors have a profound effect on how people age and what options are available to them. Most older women experience disadvantages that have significant effects on their later years. These include:

- older women report higher levels of chronic conditions than men

- a majority of older women live on low incomes and have few assets

- fewer older women than men are employed

- older women are less likely to own their own accommodation
- more older women live in social and/or rural isolation. ${ }^{2}$ The Older Women's Network (OWN) is a communitybased national organisation committed to promoting the rights, dignity and wellbeing of older women. The organisation has a strong advocacy role, promotes a positive image of older women, and provides and disseminates information for and about older women.

OWN has been developing and promoting a wellness model for older women since 1995 . The model involves older women identifying their health needs and, in response, designing and implementing programs and activities that are managed and delivered by older women. The model focuses on diversity, consultation and the importance of older women as facilitators and role models. $^{3}$

Centres in Bankstown and North Sydney have received funding from various sources, including the NSW Department of Health, to support a wide range of wellness activities. An important aspect of these centres, and the wellness model, is to reduce social isolation by recognising the important role that older women have in the community.

In July 1999, a statewide forum was held at Sydney University to discuss models of wellness and to explore 